\title{
Harmonic Equivalence of the Impulse Loads in Vibration Fatigue
}

\author{
Primož Ogrinec - Janko Slavič゙ - Miha Boltežar \\ University of Ljubljana, Faculty of Mechanical Engineering, Slovenia
}

\begin{abstract}
In vibration fatigue, three unique types of loads are typical: random, harmonic and impulse. In an application any of these loads are possible. A fatigue-life analysis is possible in the time and frequency domains using the frequency-response function of a structure. Recent studies demonstrated that the impulse loads influence the accuracy of a fatigue-life prediction in the frequency domain. The focus of this research is a theoretical study of an equivalent harmonic load to the impulse load on a single-degree-of-freedom system in order to investigate the feasibility of impulse loads in vibration testing. This research shows that there is a relationship between the impulse and harmonic loads that is related to the underlying dynamic properties (e.g., damping, natural frequency). Based on a theoretical analysis an experimental procedure was developed for both cases of excitation, which was able to confirm the theoretical analysis. Using the modal decomposition the single-degree-of-freedom approach can be generalized to multiple-degrees-of-freedom systems.
\end{abstract}

Keywords: vibration fatigue, random loads, spectral methods, fatigue life, stationary and non-stationary loading, non-Gaussian loading, vibration testing

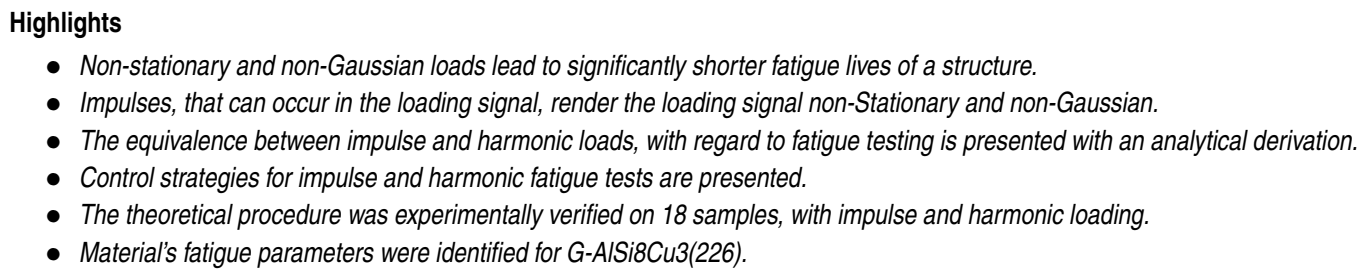

\section{INTRODUCTION}

As structures are becoming lighter and loads optimised, the effects of structural dynamics [1] and random loads on the fatigue life of flexible structures are becoming more important. This is known as vibration fatigue and has been the subject of various studies in recent years [2] to [7].

Vibration fatigue is focused in loads well below the yield stress (i.e., high-cycle fatigue), which is typically researched in the time domain (e.g., rainflow-counting algorithm [8]) or in the frequency domain (e.g., the narrow band [9], Dirlik [2] or Tovo-Bennasciutti methods [5] and [3]). When studying fatigue life in the frequency domain it is common to assume that the excitation signals and consequently the stress response of a structure are Gaussian and stationary [10] and [11].

In recent years great efforts have been made to develop the frequency-counting methods in the analysis of the fatigue life of structures excited with non-Gaussian and non-stationary excitation signals [12] to [16]. Tovo and Bennasciutti studied non-stationary switching random loads [4]. Song and Wang [17] presented a spectral-moment-equivalence lumped block method that improves the accuracy of the fatigue-life analysis for non-stationary, non-Gaussian loads and incorporates the material parameters into the equivalent spectral moments formula. Bracessi et al. [18] and Niu et al. [19] researched the influence of load Kurtosis and skewness on the damage rate in the case of non-Gaussian signals; Wolfsteiner and Sedlmair [20] and Cianetti et al. [21] presented correction factors based on those two characteristics of the loading signal.

In real cases it is common to experience some forms of non-Gaussian loading [22], which can also be the result of the impulses superimposed on the random loading of a structure [23]. These impulses can be the consequence of geometric non-linearities, contact conditions, clearances, wear, etc.

While the fatigue life under a combination of harmonic and random loads can be studied in the frequency domain [24], [25] and [6], the effects of these impulse loads are not well researched. The presence of impulses renders the signal non-stationary. Capponi et al. [15] and Palmieri et al. [16] noted that in the case of such signals the fatigue-life assessments with spectral methods in the frequency domain return a significantly longer life prediction than were observed in the experimental testing. Hence, the development of new methods that can account for the presence of impulses in the stress response is of great importance. 
As was recently shown by Ogrinec et al. [23] the most influential parameters on the accuracy of the frequency-domain methods on the fatigue-life prediction at impulse excitation are: the significant natural frequency, the length of the impulse [26], the coefficient of damping, the modal mass, and the material parameters of the Wöhler curve. For that reason, accurate identification of the material's fatigue parameters is crucial. The material parameters, however, can sometimes vary based on the method used to obtain them. It is known, for instance, that the strain rate can significantly influence measurements of the yield stress and the ultimate tensile strength [27]. Similarly, the identification of the material's fatigue parameters can be influenced [28].

For reasons of simplicity, it is common to use a harmonic loading signal for fatigue testing [29], although some other loading signals are possible [30] and [31]. However, since the influence of the material's fatigue parameters on the fatigue-life estimation's accuracy was proven [23], the question of the validity of the parameters of the Wöhler curve obtained with a harmonic test remains open. Therefore, an experimental exploration of the effects of impulse loading on the identification of material's fatigue properties is necessary.

The main goal of this study is to analyse the possibility to determine the parameters of the Wöhler curve, based on a fatigue test, where the sample is excited with impulses. An experimental setup is presented, where only one significant mode shape was excited. The system is free to respond to the half-sine impulse; therefore, the sample experiences a variety of cycles with varying amplitudes. To produce an equivalent load, the hypothesis of a linear accumulation of damage [32] is assumed. The parameters of the Wöhler curve are compared to an equivalent test, where the sample is excited harmonically.

This manuscript is organised as follows. Sec. 1 presents the theoretical background. The theoretical comparison between the damage accumulation due to harmonic and impulse excitationx is presented in Sec. 2. In Sec. 3 the experimental setup with control algorithms for both load cases is presented. The results are presented in Sec. 4. Sec. 5 draws the conclusions.

\section{THEORETICAL BACKGROUND}

When a dynamic system is excited in the frequency range of its natural frequencies the response of the system is amplified. If the system is excited with a half-sine impulse, the frequency range of the excitation is determined with the length of the impulse. To take advantage of the response amplification, which is particularly useful in fatigue testing, the impulse has to be specified with this range of excitation in mind.

However, when the system is excited harmonically, the frequency of excitation has to be close enough to a significant natural frequency to obtain the dynamic amplification.

\subsection{Structural Dynamics}

Any real structure can be regarded as a continuum and can therefore be modelled as a multi-degrees-of-freedom (MDOF) system. The equation of motion for a general MDOF structure is [33], [34]:

$$
\mathbf{M} \ddot{\mathbf{x}}+\mathbf{C} \dot{\mathbf{x}}+\mathbf{K} \mathbf{x}=\mathbf{f}
$$

where $\mathbf{M}, \mathbf{C}$ and $\mathbf{K}$ are the mass, viscous damping and stiffness matrices of the structure, respectively. $\mathbf{f}$ represents the vector of the excitation forces and $\mathbf{x}$ is the displacement vector of the stucture's degrees of freedom. After introducing the proportional viscous damping $\xi$ and modal coordinates $\mathbf{q}$, the equations of motion become uncoupled [35].

$$
\mathbf{I} \ddot{\mathbf{q}}+\left[\backslash 2 \xi \omega_{0} \backslash \dot{\mathbf{q}}+\left[\backslash \omega_{0}^{2} \backslash\right] \mathbf{q}=\boldsymbol{\Phi}^{T} \mathbf{f},\right.
$$

where:

$$
\mathbf{x}=\boldsymbol{\Phi} \mathbf{q}
$$

$\boldsymbol{\Phi}$ is the mass-normalized modal matrix [35]. I represents the identity matrix, $\backslash 2 \xi \omega_{0} \backslash$ is the diagonal damping matrix and $\left[\backslash \boldsymbol{\omega}_{0}^{2} \backslash\right]$ is the diagonal matrix of the natural frequencies. For the $i$-th modal coordinate $q_{i}$ the uncoupled equation of motion is [35]:

$$
\ddot{q}_{i}+2 \xi_{i} \omega_{0, i} \dot{q}_{i}+\omega_{0, i}^{2} q_{i}=\Phi_{i}^{T} \mathbf{f},
$$

where $\Phi_{i}$ is $i$-th mass-normalized eigenvector. It is worth noting that the transformation to the modal coordinates transforms a MDOF system with $N$ degrees of freedom, to $N$ decoupled single-degree-of-freedom (SDOF) systems.

\subsection{Impulse Response}

When a SDOF system [35] is excited with an ideal unit impulse, which can be defined with the Dirac delta function:

$$
\delta(t)= \begin{cases}\infty, & t=0 \\ 0, & t \neq 0\end{cases}
$$


the system responds with the impulse response function $g(t)$ [33] and [35]:

$$
g(t)=\frac{\mathrm{e}^{-\delta \omega_{0} t} \sin \left(\sqrt{1-\delta^{2}} \omega_{0} t\right)}{\sqrt{1-\delta^{2}} \omega_{0}} .
$$

When the damping coefficient is small $(\delta<<1$, $\sqrt{1-\delta^{2}} \approx 1$ ) then Eq. (6) simplifies to:

$$
g(t)=\frac{\mathrm{e}^{-\delta \omega_{0} t} \sin \left(\omega_{0} t\right)}{\omega_{0}} .
$$

In order to obtain the response for a general force excitation $f(t)$, the convolution integral of the impulse $f(t)$ and the impulse-response function $g(t)$ are required [36].

$$
x(t)=f(t) * g(t)=\int_{-\infty}^{t} f(\tau) g(t-\tau) \mathrm{d} \tau,
$$

where $t$ is the time variable and $x(t)$ is the time response of the SDOF system.

The half sine impulse excitation and the impulse load of a SDOF structure are presented in Fig. 1.

\subsection{Fatigue-life Estimation}

In order to obtain the fatigue damage in the case of an impulse excitation a counting method has to be employed. In this paper the rainflow counting method [8] will be used in combination with the hypothesis of linear damage accumulation [32] and [37]. Here, the basics (used later in this paper) of the time-domain high-cycle approach to the fatigue-life estimation are presented (for details see, e.g. [38]).

The rainflow algorithm [8] transforms the stress-time history into a series of stress reversals. After the stress-time history is determined, the Miners rule of damage accumulation is applied and the damage is calculated as:

$$
D^{R F}=\sum_{i=1}^{P} \frac{n_{i}}{N_{i}}
$$

where $P$ is the number of ranges in the stress-reversal series that are identified by the rainflow algorithm and $n_{i}$ is the number of stress reversals at each individual stress level. Together with the fatigue parameters, which determine the expected number of cycles $N_{i}$ at a stress level $\sigma_{i}$, Eq. (9) leads to the accumulated damage in the structure. The number of expected cycles $N_{i}$ that a structure survives at the stress level $\sigma_{i}$ is theoretically described with the Wöhler curve [39]:

$$
\sigma_{i}^{k} N_{i}=C
$$

where $k$ and $C$ are the material's fatigue parameters. It is important to be aware that this simple S-N relationship does not account for the material's endurance limit and can only be used when dealing with high-cycle fatigue [40] or with materials that do not exhibit a fatigue limit.

\section{HARMONIC EQUIVALENCE OF THE IMPULSE LOADS}

\subsection{Damage at impulse excitation}

In order to compare the harmonic and impulse excitations, the accumulated fatigue damage, which is the consequence of the individual loads, has to be determined analytically. The modal decomposition, as presented in Sec. 1, makes it possible to apply the methods developed for the single-degree-of-freedom (SDOF) system, to multiple-degree-of-freedom (MDOF) systems [35]. As was shown in [23] the dynamic stress response to an impulse excitation can be simplified to a scaled impulse-response function Eq. (7) for the analysis of the fatigue damage in the time domain, assuming the impulses are well separated, meaning that the response of the impulse is completely damped before the next impulse occurs. Therefore, the relatively complex solution of the convolution integral Eq. (8) is not necessary. The stress response of the structure $\sigma_{I}$ can be written as a scaled impulse-response function:

$$
\sigma_{I}(t)=\sigma_{P} \frac{\mathrm{e}^{-\delta \omega_{0} t} \sin \left(\omega_{0} t\right)}{\omega_{0}},
$$

for small coefficients of damping $\delta<<1$. In Eq. (11) the $\omega_{0}$ stands for the natural frequency of a SDOF system and $\sigma_{P}$ the peak stress of the response (envelope). As the rainflow algorithm [8] considers only the peaks and valleys of the stress response, Eq. (11) can be further simplified for the peaks:

$$
\sigma_{I}(i)=\mathrm{e}^{-\frac{1}{2} \pi \delta(2 i+1)}(-1)^{i} \sigma_{p},
$$

where $i$ is an integer. In this manner the stress response can be discretized to a series of local maximum and minimum values of the stress response, also known as a turning-point sequence. Since the rainflow algorithm requires only the amplitudes of the extreme stress values, the individual stress cycles $\chi_{i}$ can be defined as the summation of the absolute values of the successive extreme points:

$$
\chi_{i}=\frac{1}{2}\left(\sigma_{I}(i)+\sigma_{I}(i+1)\right) .
$$

After introducing Eq. (12), Eq. (13) becomes:

$$
\chi_{i}=\frac{1}{2}\left(\mathrm{e}^{\pi \delta}+1\right) \mathrm{e}^{-\frac{1}{2} \pi \delta(2 i+3)} \sigma_{p} .
$$




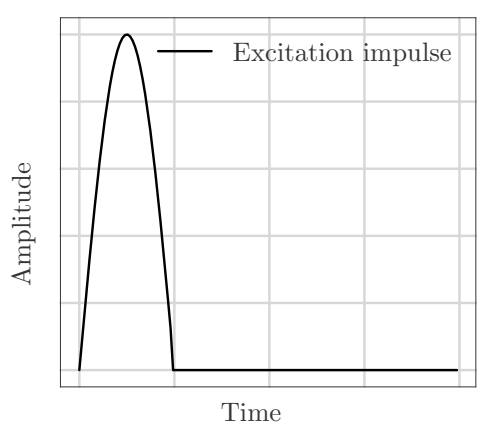

a)

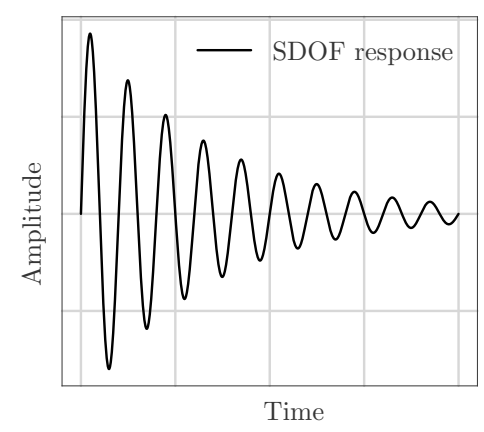

b)

Fig. 1. a) Normalised half-sine impulse excitation, and b) the impulse response of a SDOF structure

The Palmgren-Miner rule of linear damage accumulation Eq. (9) can now be employed to determine the damage $D$ as:

$$
D=N_{I} \sum_{i=0}^{\infty} \frac{1}{N_{i}}
$$

where $N_{i}$ is the number of cycles until failure at the level $\chi_{i}$ and $N_{I}$ is the number of impulse excitations (resulting in the impulse-response cycle load $\chi_{i}$ ). By using the definition of the cycles Eq. (14) and the Wöhler curve Eq. (10), the respective number of cycles $N_{i}$ that the structure would endure for any given stress-cycle amplitude can be determined as:

$$
D_{I}=N_{I} \sum_{i=0}^{\infty}\left(\frac{\chi_{i}^{k}}{C}\right) \text {. }
$$

The Cauchys criterion for convergence [41] states that for each $\varepsilon>0$ a pair $k>n$ exists for which:

$$
\left|\sum_{j=n+1}^{r} \chi_{j}\right|=\left|\chi_{n+1}+\chi_{n+2}+\cdots+\chi_{r}\right|<\varepsilon .
$$

Since the stress cycles of a damped SDOF structure limit towards $0, \lim _{n \rightarrow \infty} \chi_{n}=0$, the Cauchys criterion is satisfied and the sum in Eq. (16) is final:

$$
D_{I}=-\frac{N_{I} 2^{-k}\left(\mathrm{e}^{-\frac{1}{2}(3 \pi \delta)}\left(\mathrm{e}^{\pi \delta}+1\right) \sigma_{p}\right)^{k}}{C\left(\left(\mathrm{e}^{-\pi \delta}\right)^{k}-1\right)} .
$$

\subsection{Damage at Harmonic Excitation}

If the load on the structure is harmonic with a constant stress amplitude $\sigma_{e q}$, using the Palmgren-Miner rule for linear damage accumulation [32], the cumulative damage is:

$$
D_{H}=N_{H} \frac{\sigma_{e q}^{k}}{C}
$$

where $N_{H}$ is the number of stress cycles at $\sigma_{e q}$.

\subsection{The Equivalent Impulse Load to Harmonic Excitation}

Here, the damage $D_{I}$ Eq. (18) of the $N_{I}$ repetitions of impulse excitation, where the response load is a damped impulse response as shown in Fig. 1, will be related to the damage $D_{H}$ Eq. (19) due to the harmonic excitation with $N_{H}$ harmonic cycles at amplitude $\sigma_{e q}$ :

$$
D_{I}=D_{H} .
$$

Using Eqs. (18) and (19) and the assumption that the fatigue parameters are the same for impulse and harmonic excitations:

$$
-\frac{N_{I} 2^{-k}\left(\mathrm{e}^{-\frac{1}{2}(3 \pi \delta)}\left(\mathrm{e}^{\pi \delta}+1\right) \sigma_{p}\right)^{k}}{C\left(\left(\mathrm{e}^{-\pi \delta}\right)^{k}-1\right)}=N_{H} \frac{\sigma_{e q}^{k}}{C},
$$

which can be simplified to:

$$
\sigma_{e q}=\cosh \left(\frac{\pi \delta}{2}\right) \sigma_{p}\left(\frac{N_{I}}{N_{H}\left(\mathrm{e}^{\pi \delta k}-1\right)}\right)^{1 / k} .
$$

For small coefficients of damping $\delta<<1$, which is often the case in real structures, this can be further simplified to:

$$
\sigma_{e q}=\sigma_{p}\left(\frac{N_{I}}{N_{H}\left(\mathrm{e}^{\pi \delta k}-1\right)}\right)^{1 / k} .
$$

As can be seen from this derivation, the influencing factors on the relation between the impulse and harmonic loads are the coefficient of damping $\delta$, the amplitudes $\sigma_{e q}$ for harmonic and $\sigma_{P}$ impulse loads, the number of harmonic cycles $N_{H}$ and impulses $N_{I}$ and the slope of the Wöhler curve $k$. This analytical derivation proves that for any impulse-response load there exists an equivalent harmonic load that yields the 
same damage. Eq. (22) can be rearranged into a form that resembles the notation for the Wöhler curve:

$$
\frac{\sigma_{e q}}{\sigma_{P}}=\left(\frac{1}{\mathrm{e}^{\pi \delta k}-1}\right)^{1 / k}\left(\frac{N_{I}}{N_{H}}\right)^{1 / k} .
$$

\section{EXPERIMENTAL SETUP}

For the experimental validation an electrodynamic shaker capable of impulse and harmonic excitations with closed-loop control was used. In order to obtain the parameters of the Wöhler curve at impulse excitation, the sample's mode shape of interest must be excited with a translational movement in the axis of the shaker. Additionally, the sample's natural frequency of interest must be distinct, well separated from the other natural frequencies and be within the shaker's frequency range [42]. The area where the maximum stresses in the sample occur, must be on a surface where strain-gauge measurements are possible. It is also preferable to correlate strain with the relative displacements, since they can be measured throughout the test more reliably [40],[42].

The Y-shaped sample was chosen as it meets all of these criteria. Its natural frequencies are well separated; therefore, only one mode can be excited. Subsequently, the sample can be regarded as a SDOF system. The specimen consists of three rectangular cross-sections, $10 \mathrm{~mm} \times 10 \mathrm{~mm}$ in size, that are arranged at $120^{\circ}$ around the main axis. A circular hole in the centre ensures the fatigue zone is concentrated in the centre between the arms of the specimen. The samples are cast from the aluminium alloy G-AlSi8Cu3(226). The thickness is determined by milling and the overall shape by wire EDM (electrical discharge machining). The fatigue zones, which can be clearly seen in Fig. 2, are additionally ground and polished in order to remove any initial surface defects, which could start the crack growth prematurely. On the arms of the specimen two steel dead-weights can be positioned; using different dead-weights the natural frequency and the damping of the system can be changed. The design idea of the specimen is explained in detail in [40]. A total of 18 samples were experimentally tested: 9 of them at impulse excitation and the other 9 samples at harmonic excitation, similar to the description in [23] and [40].

During preparation of the Y-sample, extreme care was taken while machining, as well as during the preparation of the fixture of the sample in order to excite only one significant mode. The material G-AlSi8Cu3(226) was chosen because of its good casting properties that reduce the porosity of the cast sample. The material is, however, notorious for relatively large silicon inclusions, which affect the variance in the fatigue lives between samples.

The natural frequency of the system was varied with the selection of different weights; three different system setups were researched (each setup was researched with 3 samples with impulse and 3 with harmonic excitation), see Tables 1 and 2 for the natural frequency of the samples, while other parameters given in the table will be discussed later.

\subsection{Impulse Test}

During the fatigue testing the sample was excited with well-separated half-sine impulses. In the first step an experimental modal analysis was performed to obtain the natural frequencies of the samples. The duration of the impulse was determined with:

$$
t_{i}=\frac{2 \pi}{a \omega_{0}}
$$

where $\omega_{0}$ is the focused natural frequency that was excited and $a$ is a constant $a=2$, as proposed in [23]. Due to the fatigue damage the natural frequency will decrease. In vibration fatigue a change in the natural frequency of $2 \%$ is considered as fatigue failure [43]; with the small change it is reasonable to assume that the mechanical system is still linear. The control loop for impulse testing is presented in Fig. 3. If $x_{S}$ is the amplitude of displacement of the shaker base and $x_{A}$ is the amplitude of displacement of one of the Y-sample arms, then the relative displacement amplitude $\Delta x$ can be related to the stress $\sigma$ in the fatigue zone via the coefficient $k_{\sigma}$ [23]:

$$
k_{\sigma}=\frac{\sigma}{\Delta x}=\frac{E \varepsilon \omega^{2}}{\ddot{x}_{S}-\ddot{x}_{A}},
$$

where $\varepsilon$ is the strain, measured in the fatigue zone, $\omega$ is the frequency of excitation, $\ddot{x}_{A}$ is the acceleration of the arm of the sample, $\ddot{x}_{S}$ is the acceleration of the armature of the shaker, and $E$ is the elastic modulus. The relation between the accelerations and deflections is simple since the response of the structure is harmonic in both excitation cases. This calibration was performed on a separate sample, so as not to induce any initial damage to the samples that were used for the identification of the material's fatigue properties.

As the natural frequency was well excited in the impulse testing, it was possible to identify and track the natural frequency for every impulse-excitation response. Thus it was possible to identify the critical 


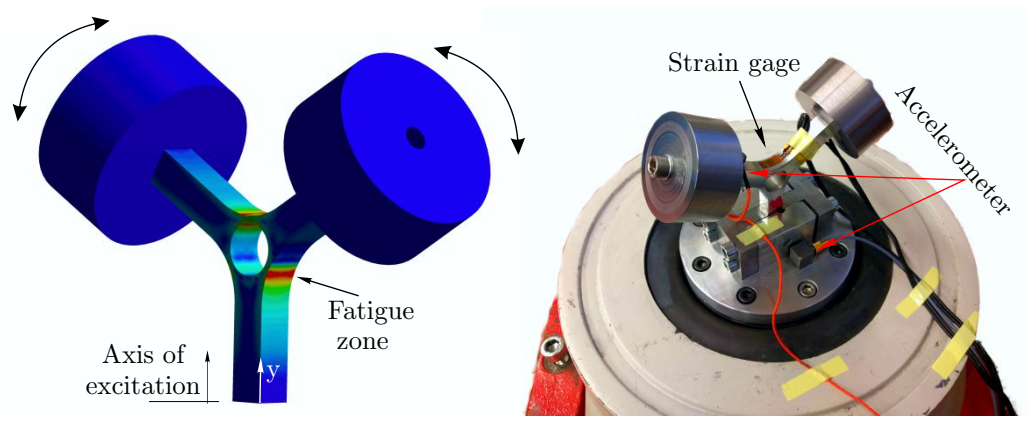

Fig. 2. Experimental setup

Table 1. Samples for the impulse test

\begin{tabular}{ccrrrrrc}
\hline Sample nr. & Natural frequency $[\mathrm{Hz}]$ & $\sigma_{P}[\mathrm{MPa}]$ & $N_{I}[/]$ & $\delta^{\text {init }}[/]$ & $D_{I}^{\text {init }}[]$ & $\delta^{\text {fin }}[/]$ & $D_{I}^{\text {fin }}[]$ \\
\hline 1.1 & 300.0 & 126.1 & 7300 & 0.0241 & 1.64 & 0.0301 & 1.19 \\
\hline 1.2 & 300.0 & 88.34 & 155000 & 0.0218 & 1.29 & 0.0236 & 1.16 \\
\hline 1.3 & 300.0 & 125.9 & 6460 & 0.0246 & 1.38 & 0.0253 & 1.33 \\
\hline 2.1 & 330.0 & 88.4 & 105560 & 0.0178 & 1.16 & 0.0188 & 1.08 \\
\hline 2.2 & 334.0 & 84.0 & 226180 & 0.0189 & 1.40 & 0.0363 & 0.55 \\
\hline 2.3 & 328.0 & 83.2 & 233080 & 0.0165 & 1.57 & 0.0186 & 1.34 \\
\hline 3.1 & 402.0 & 74.2 & 309660 & 0.0145 & 0.82 & 0.0153 & 0.76 \\
\hline 3.2 & 398.5 & 78.3 & 120420 & 0.0100 & 0.83 & 0.0169 & 0.44 \\
\hline 3.3 & 402.0 & 82.7 & 206140 & 0.0170 & 1.27 & 0.0183 & 1.15 \\
\hline
\end{tabular}

Table 2. Samples for the harmonic test

\begin{tabular}{ccrrrr}
\hline Sample nr. & Natural frequency $[\mathrm{Hz}]$ & $\delta[]$ & $\sigma_{H}[\mathrm{MPa}]$ & $N_{H}[]$ & $D_{H}[/]$ \\
\hline 4.1 & 298.0 & 0.0276 & 55.3 & 13122486 & 1.11 \\
\hline 4.2 & 300.0 & 0.0284 & 65.0 & 2629897 & 1.06 \\
\hline 4.3 & 300.0 & 0.0232 & 50.0 & 37004975 & 1.19 \\
\hline 5.1 & 331.0 & 0.0169 & 60.3 & 4463862 & 0.83 \\
\hline 5.2 & 333.0 & 0.0171 & 40.1 & 508457676 & 1.94 \\
\hline 5.3 & 330.0 & 0.0181 & 49.9 & 26809448 & 0.85 \\
\hline 6.1 & 400.5 & 0.0138 & 44.2 & 68807660 & 0.68 \\
\hline 6.2 & 399.0 & 0.0145 & 80.0 & 284920 & 0.85 \\
\hline 6.3 & 402.0 & 0.0121 & 46.1 & 67629488 & 1.00 \\
\hline
\end{tabular}

damage of the sample when the natural frequency fell by $2 \%$.

During the fatigue test, as the damage increases, the damping can change [29]. For an accurate damage estimation it is therefore important to identify the damping coefficient throughout the test. Table 1 shows the initial $\delta^{\text {init }}$ and the final $\delta^{\text {fin }}$ values of the coefficient of damping. Due to the open-loop strategy, also the stress load, estimated from the two accelerometers, can slightly change. During the fatigue test, a peak amplitude deviated less than to $2 \%$ for all samples, but the sample 1.1, a $6 \%$ decrease was observed.

\subsection{Harmonic Test}

Under the harmonic test, the samples were excited harmonically with a frequency close to the significant natural frequency. A control strategy was used, where the phase shift $\Phi$ between the accelerometer mounted on the shaker's armature and the arm of the sample (see Fig. 2) was monitored to adjust the excitation frequency and to control the stress amplitude [40], see Fig. 4. During the harmonic test, the amplitude and natural frequency were updated every $500 \mathrm{~ms}$.

The damping coefficient does not influence the fatigue-life prediction in the case of harmonic excitation. The excitation amplitudes can, however, still vary. Although a closed-loop control algorithm was used, the excitation amplitudes could vary by up to $0.5 \%$.

\subsection{Damage Criteria}

As the structural dynamics of the sample changes long before its complete failure, it is practical to identify 


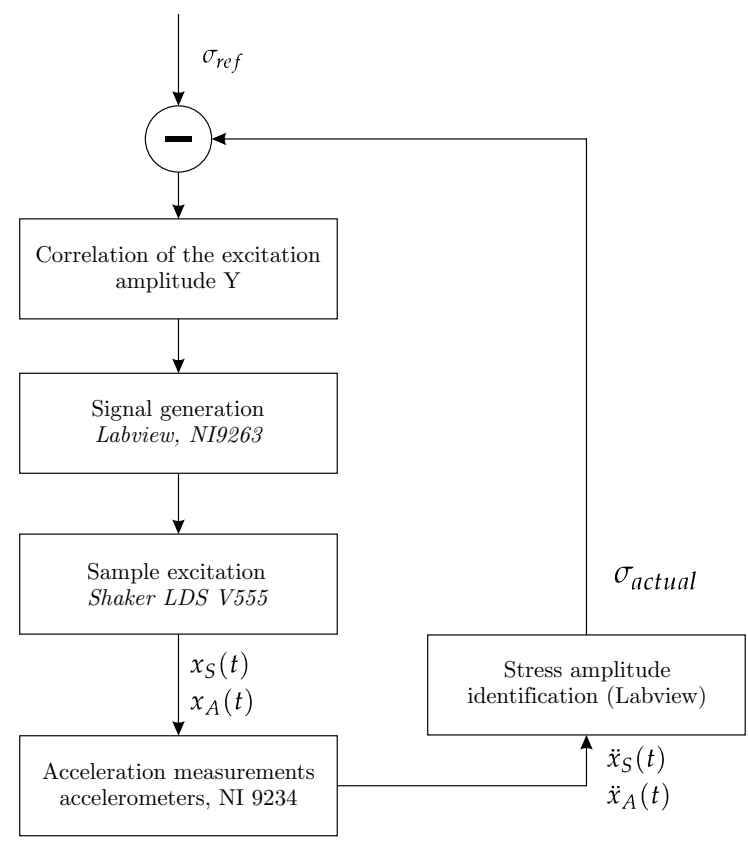

Fig. 3. Control loop for impulse excitation

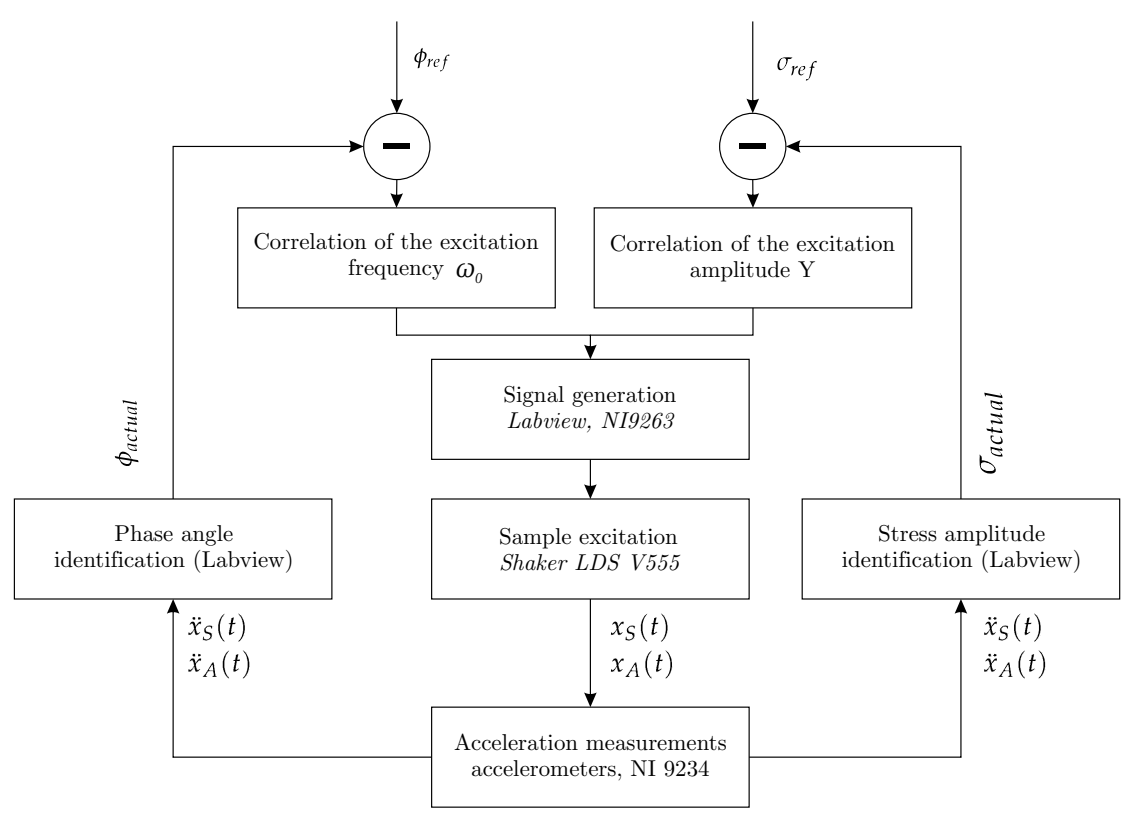

Fig. 4. Control loop for harmonic excitation

a failure when the natural frequency starts to change rapidly [40] and [42]. Therefore, in this research a drop of $2 \%$ in the natural frequency was considered as a failure. For details about the failure on damage identification from the natural frequency, the interested reader is referred to [44].
During the impulse test the identification of the natural frequency is fairly straight forward, as it can be identified as the frequency at the peak value in the Fourier transform of the stress signal, see Fig. 5. During the harmonic test, the natural frequency had to be identified indirectly, from the 
phase difference between the signals of the top and bottom accelerometers. As the frequency falls, the excitation frequency required to keep the same dynamic gain and the phase shift between the signals falls likewise. Therefore, the fall of the significant natural frequency can be determined by recording the excitation frequency. The tracked excitation frequency is shown in Fig. 6.

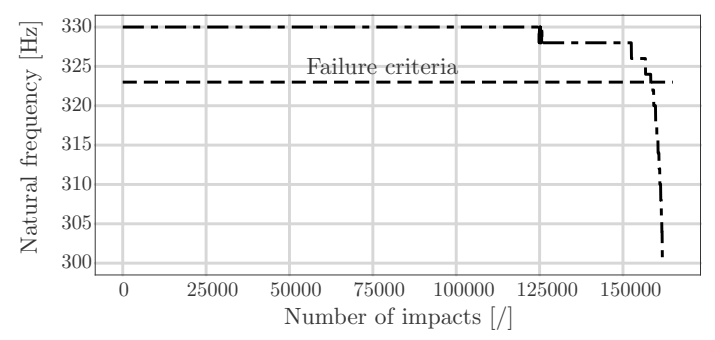

Fig. 5. Decreasing of natural frequency during the impulse fatigue test

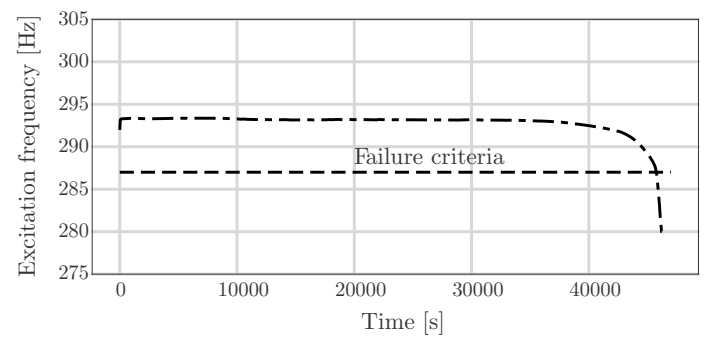

Fig. 6. Fall of excitation frequency during harmonic excitation.

\section{RESULTS}

\subsection{Identification of the Wöhler Curve}

Since the goal of this paper is to prove the equivalence of the impulse and harmonic loads, the Wöhler curve was identified on the harmonic test results, only. The fatigue parameters for the equiprobability curve identified on the harmonic test results were:

$$
\begin{aligned}
C_{\mathrm{H}} & =7.2450 \times 10^{23}, \\
k_{\mathrm{H}} & =9.6347 .
\end{aligned}
$$

The parameters were identified with the cost function:

$$
\varepsilon(\tilde{k}, \tilde{C})=\min \left[\sum_{i=1}^{S} D_{i}(\tilde{k}, \tilde{C})-1\right],
$$

where $S$ is the number of samples, $\tilde{k}$ and $\tilde{C}$ are the material parameters used in each individual iteration of the optimisation, and $\varepsilon(\tilde{C}, \tilde{k})$ is the error between the optimal value of the damage and the damage in current iteration.

\subsection{Comparing the Two Loading Strategies}

With the fatigue parameters obtained from the harmonic test Eq. (27), Eq. (19) is used to theoretically estimate the damage for the harmonic test. As the fatigue parameters were fitted to the experimental results of the harmonic test it is expected that $D_{H}$ would be close to 1 . From Table 2 we can see that this is the case for most of the samples; the deviation from 1 is reasonable and expected in the fatigue test.

It is reasonable to assume that the fatigue parameters between the harmonic and the impulse test are the same. Therefore, the fatigue parameters obtained from the harmonic test Eq. (27) can be used with the damage estimation at impulse excitation Eq. (18). The resulting damage $D_{i}^{\text {init }}$ and $D_{i}^{\text {fin }}$ based on the damping identified at the beginning and the end of the test are given in Table 1. We can see that the damage is reasonably close to 1 .

This experimental result validates the theoretical relation between the impulse and the harmonic load introduced in Eq. 24.

\section{CONCLUSIONS}

The harmonic loads for high-cycle fatigue are well understood and can be theoretically and experimentally researched relatively easily. The contrary is true for the impulse loads; the impulse excitation is frequently exciting mechanical systems, leading to a damped free response related to the structural dynamic's of the system. Based on the structural dynamics theoretical background and classic fatigue theory in the time domain, a theoretical relation between the vibration-fatigue damage in the case of the impulse load and the harmonic load is introduced.

The theoretical model was experimentally evaluated using the Y-sample. A total of 18 samples were experimentally tested; 9 for harmonic loads and 9 for impulse excitation. The samples were grouped in sets of 3 . Using different mass loadings to the Y-sample, three different dynamic systems were researched (different natural frequencies and damping). Based on the time-domain experimental data from the harmonic test, the fatigue parameters were identified. The identified material parameters were then used to recalculate the damage at failure for every individual sample, for both excitation strategies. The identified damage was reasonably close to 1 confirming the introduced theoretical relation between the impulse and harmonic excitations.

The introduced relation between the impulse and harmonic excitations can be used for the 
further development of frequency-counting methods, specifically with impulse loads as a source of non-stationarity.

\section{ACKNOWLEDGEMENTS}

The authors acknowledge the partial financial support from the Slovenian Research Agency (research core funding No. P2-0263).

\section{REFERENCES}

[1] Luznar, J., Slavič, J., Boltežar, M. (2019). Structure-borne noise at PWM Excitation using an extended field reconstruction method and modal decomposition. Strojniški vestnik - Journal of Mechanical Engineering, vol. 65, no. 9, p. 471-481, DOI:10.5545/sv-jme.2019.6115.

[2] Dirlik, T. (1985). Application of Computers in Fatigue Analysis. $\mathrm{PhD}$ thesis, University of Warwick, Warwick.

[3] Benasciutti, D (2004). Fatigue Analysis of Random Loadings. $\mathrm{PhD}$ thesis, University of Ferrara, Ferrara.

[4] Benasciutti, D., Tovo, R. (2007). Frequency-based fatigue analysis of non-stationary switching random loads. Fatigue \& Fracture of Engineering Materials \& Structures, vol. 30, no. 11, p. 1016-1029, DOI:10.1111/j.1460-2695.2007.01171.x.

[5] Benasciutti, D., Tovo, R. (2018). Frequency-based analysis of random fatigue loads: Models, hypotheses, reality. Material Science and Engineering Technology, vol. 49, no. 3, p. 345367, D0l:10.1002/mawe.201700190.

[6] Mršnik, M., Slavič, J., Boltežar, M. (2013). Frequency-domain methods for a vibration-fatigue-life estimation-application to real data. International Journal of Fatigue, vol. 47, p. 8-17, D0I:10.1016/j.ijfatigue.2012.07.005.

[7] Mršnik, M., Slavič, J., Boltežar, M. (2018). Vibration fatigue using modal decomposition. Mechanical Systems and Signal Processing, vol. 98, p. 548-556, D0l:10.1016/j. ymssp.2017.03.052

[8] Matsuishi, M., Endo, T. (1968). Fatigue of metals subjected to varying stress. Japan Society of Mechanical Engineers, vol. 68 , no. 2, p. 37-40.

[9] Miles, J.W. (1954). On structural fatigue under random loading. Journal of the Aeronautical Sciences, vol. 21, no. 11, p. $753-762$, DOl:10.2514/8.3199.

[10] Newland, D.E. (2012). An Introduction to Random Vibrations, Spectral \& Wavelet Analysis. Dover Publication, Mineola.

[11] Bendat, J., Piersol, A. (2011). Random Data: Analysis and Measurement Procedures, vol. 729, John Wiley \& Sons, Hoboken.

[12] Braccesi, C., Cianetti, F., Tomassini, L. (2017). Fast evaluation of stress state spectral moments. International Journal of Mechanical Sciences, vol. 127, p. 4-9, D0l:10.1016/j. ijmecsci.2016.11.007.

[13] Böhm, M., Łagoda, T. (2018). Fatigue life assessment with the use of the spectral method for non-Gaussian loading histories with the use of the energy parameter. Journal of Machine Construction and Maintenance, vol. 1, p. 27-31.
[14] Fan, Z., Jiang, Y., Zhang, S., Tao, J., Chen, X. (2017). Research on vibration fatigue of carbon fibre-reinforced composites under non-Gaussian random load. Prognostics and System Health Management Conference, p. 1-8, D0l:10.1109/ PHM.2017.8079154.

[15] Capponi, L, Česnik, M., Slavič, J., Cianetti, F., Boltežar, M. (2017). Non-stationarity index in vibration fatigue: Theoretical and experimental research. International Journal of Fatigue, vol. 104, p. 221-230, D0l:10.1016/j.ijfatigue.2017.07.020.

[16] Palmieri, M., Česnik, M., Slavič, J., Cianetti, F., Boltežar, M. (2017). Non-Gaussianity and non-stationarity in vibration fatigue. International Journal of Fatigue, vol. 97, p. 9-19, Dol:10.1016/j.ijfatigue.2016.12.017.

[17] Song, X., Wang, S. (2019). A novel spectral moments equivalence based lumping block method for efficient estimation of offshore structural fatigue damage. International Journal of Fatigue, vol. 118, p. 162-175, D0l:10.1016/j. ijfatigue.2018.09.016.

[18] Braccesi, C., Cianetti, F., Lori, G., Pioli, D. (2009). The frequency domain approach in virtual fatigue estimation of non-linear systems: The problem of non-Gaussian states of stress. International Journal of Fatigue, vol. 31, no. 4, p.766775, Dol:10.1016/j.ijfatigue.2008.03.007.

[19] Niu, Q., Yang, S., Li, X. (2018). An empirical mode decomposition-based frequency-domain approach for the fatigue analysis of nonstationary processes. Fatigue \& Fracture of Engineering Materials \& Structures, vol. 41, no. 9 , p. 1980-1996, Dol:10.1111/ffe.12836.

[20] Wolfsteiner, P., Sedlmair, S. (2015). Deriving Gaussian fatigue test spectra from measured non Gaussian service spectra. Procedia Engineering, vol. 101, p. 543-551, D0l:10.1016/j. proeng.2015.02.065.

[21] Cianetti, F., Palmieri, M., Braccesi, C., Morettini, G. (2018). Correction formula approach to evaluate fatigue damage induced by non-Gaussian stress state. Procedia Structural Integrity, vol. 8, p. 390-398, D0l:10.1016/j.prostr.2017.12.039.

[22] Rychlik, I. (1996). Fatigue and stochastic loads. Scandinavian Journal of Statistics, p. 387-404.

[23] Ogrinec, P., Slavič, J., Česnik, M., Boltežar, M. (2019). Vibration fatigue at half-sine impulse excitation in the time and frequency domains. International Journal of Fatigue, vol. 123, p. 308-317, D0I:10.1016/j.jfatigue.2019.02.031.

[24] Angeli, A., Cornelis, B., Troncossi, M. (2018). Synthesis of sineon-random vibration profiles for accelerated life tests based on fatigue damage spectrum equivalence. Mechanical Systems and Signal Processing, vol. 103, p. 340-351, D0l:10.1016/j. ymssp.2017.10.022.

[25] Carpinteri, A., Spagnoli, A., Vantadori, S. (2017). A review of multiaxial fatigue criteria for random variable amplitude loads. Fatigue \& Fracture of Engineering Materials \& Structures, vol. 40, no. 7, p. 1007-1036, Dol:10.1111/ffe.12619.

[26] Rizzi, S., Przekop, A., Turner, T.L. (2011). On the response of a nonlinear structure to high kurtosis non-Gaussian random loadings. $8^{\text {th }}$ International Conference on Structural Dynamics, p. 1-8.

[27] Eibl, J., Curbach, M. (1989). An attempt to explain strength increase due to high loading rates. Nuclear Engineering 
and Design, vol. 112, p. 45-50, D0l:10.1016/0029. 5493(89)90144-1.

[28] Song, W.Q., Beggs, P., Easton, M. (2009). Compressive strainrate sensitivity of magnesium-aluminum die casting alloys. Materials \& Design, vol. 30, no. 3, p. 642-648, D0l:10.1016/j. matdes.2008.05.050.

[29] Česnik, M., Slavič, J. (2014). Vibrational fatigue and structural dynamics for harmonic and random loads. Strojniški vestnik Journal of Mechanical Engineering, vol. 60, no. 5, p. 339-348, DOl:10.5545/sv-jme.2013.1831.

[30] Pahor Kos, V., Slavič, J., Boltežar, M. (2014). Fatigue damage for sweep-sine and random accelerated vibration testing. Advances in Mechanical Engineering, vol. 7, no. 2, p. 1-8, Dol:10.1155/2014/340545.

[31] Česnik, M., Slavič, J., Boltežar, M. (2016). Assessment of the fatigue parameters from random vibration testing: Application to a rivet joint. Strojniški vestnik - Journal of Mechanical Engineering, vol. 62, no. 7-8, p. 471-482, D0I:10.5545/svjme.2016.3774.

[32] Miner, M.A. (1959). Estimation of fatigue life with particular emphasis on cumulative damage. Metal Fatigue, p. 278-289.

[33] Géradin, M., Rixen, D.J. (2014). Mechanical Vibrations: Theory and Application to Structural Dynamics. John Wiley \& Sons, Hoboken.

[34] Rao, S., Yap, F.F. (2011). Mechanical Vibrations, vol. 4. Prentice Hall, Upper Saddle River.

[35] Maia, N.M.M., e Silva J.M.M. (1997). Theoretical and Experimental Modal Analysis. Research Studies Press, Taunton.
[36] Smith, S.W. (1997). The Scientist and Engineer's Guide to Digital Signal Processing. California Technical Pub., San Diego.

[37] Palmgren, A. (1924). Die lebensdauer von kugellagern. Zeitschrift des Vereines Deutscher Ingenieure (ZVDI), vol. 14, p. 339-341. (in German)

[38] Socie, D.F., Marquis, G.B. (2000). Multiaxial Fatigue. Society of Automotive Engineers, Warrendale.

[39] Wöhler, A. (1870). Über die Festigkeits-versuche mit Eisen und Stahl. Ernst and Korn, Berlin. (in German)

[40] Česnik, M., Slavič, J., Boltežar, M. (2012). Uninterrupted and accelerated vibrational fatigue testing with simultaneous monitoring of the natural frequency and damping. Journal of Sound and Vibration, vol. 331, no. 24, p. 5370-5382, D0I:10.1016/j.jsv.2012.06.022.

[41] Rudin, W. (1976). Principles of Mathematical Analysis, volume 3. McGraw-Hill, New York.

[42] George, T.J., Seidt, J., Shen, M-H H., Nicholas, T., Cross, C.J. (2004). Development of a novel vibration-based fatigue testing methodology. International Journal of Fatigue, vol. 26, no. 5, p. 477-486, Dol:10.1016/j.ijfatigue.2003.10.012.

[43] Mršnik, M., Slavič, J., Boltežar, M. (2016). Multiaxial vibration fatigue; a theoretical and experimental comparison. Mechanical Systems and Signal Processing, vol. 76-77, p. 409-423, D0l:10.1016/j.ymssp.2016.02.012.

[44] Kim, J.T., Ryu, Y.S., Cho, H.M., Stubbs, N. (2003). Damage identification in beam-type structures: frequency-based method vs mode-shape-based method. Engineering Structures, vol. 25, no. 1, p. 57-67, D0l:10.1016/S01410296(02)00118-9. 